\title{
NAS TRAMAS DO COTIDIANO: EXPERIÊNCIAS DE JOVENS E MULHERES TRABALHADORAS NA INDÚSTRIA TÊXTIL DE BLUMENAU (1958-1968)
}

Weaving everyday life: the experiences of young and female workers in the textile industry of Blumenau (1958-1968)

CRISTINA FERREIRA

http://dx.doi.org/10.1590/S2178-14942016000300009

Cristina Ferreira é mestre em História do Brasil pela Universidade Federal de Santa Catarina, doutora em História Social pela Universidade Estadual de Campinas e professora titular da Fundação Universidade Regional de Blumenau (cliocris@ gmail.com).

Artigo recebido em 26 de agosto e aprovado para publicação em 29 de setembro de 2016. 


\title{
RESUMO
}

Este artigo intenciona problematizar as relações entre norma e prática de jovens e mulheres trabalhadores da indústria têxtil de Blumenau, com ênfase na dimensão do cotidiano, repleto de estratégias criativas de atuação no mundo do trabalho. Em um universo de constantes trocas de experiência, a ênfase recaía sobre o trabalho diário e a elaboração de códigos de solidariedade, com atitudes sutis de inversão da ordem disciplinar: consumo de doces no setor de produção, uso de caixas e equipamentos para construir uma área de conversas e brincadeiras durante o expediente, além da criação de gestos que indicavam a presença de mestres e contramestres.

Palavras-CHAVE: jovens; mulheres; trabalhadores; indústria têxtil; cotidiano; Blumenau.

\begin{abstract}
The article intends to discuss the relations between codes and practices of young and female workers in the textile industry of Blumenau, with emphasis on the dimension of everyday life, full of creative strategies in the workplace. In a world of constant exchanges of experience, the emphasis fell on the daily work and the development of solidarity codes, with subtle attitudes inverting the disciplinary order: eating cakes in the production sector, using boxes and other equipment to build an area of conversation and play during the working hours, and stipulating gestures and signs that indicated the presence of headmen.
\end{abstract}

KeYwords: young; women; workers; textile industry; everyday life; Blumenau.

\section{RÉSUMÉ}

L'article examine la relation entre la règle et la pratique chez des jeunes et des femmes ouvrières de l'industrie textile de Blumenau en mettant l'accent sur la dimension de la vie quotidienne, pleine de stratégies créatives d'action. Dans un univers plein d'échanges d'expérience, l'accent était mis sur le travail quotidien et le développement de codes de solidarité, comprenant des attitudes subtiles qui renversaient la discipline: la consommation de gateaux sur le site de production; l'usage de boîtes et d'autres équipements pour construire une zone de conversation et de jeux au cours de la journée de travail, et la création de gestes et de signes pour indiquer la présence des chefs d'équipe.

Mots-CLÉs: jeunes; femmes; ouvrières; industrie textile; vie quotidienne; Blumenau. 


\section{"Eu TINHA VONTADE DE VOLTAR..., MAS TINHA QUE TRABALHAR!": A INDÚSTRIA TÊXTIL ENTRE O LAR E A FÁBRICA}

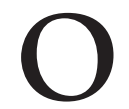
processo histórico que engloba o final da chamada "experiência democrática" (19601964) e o início da ditadura civil-militar brasileira (1964-1968) ainda constitui temática em fase de investigação na historiografia brasileira recente. Em especial, se o cerne da análise estiver direcionado para o modo como os trabalhadores urbanos atuavam no cotidiano, ângulo de abordagem dos estudos relacionados aos grandes centros urbanos do país, especialmente no eixo Rio-São Paulo. Portanto, a relevância deste estudo consiste na análise das relações cotidianas de jovens e mulheres trabalhadoras em Blumenau (SC), ${ }^{1}$ cidade industrial associada ao segmento têxtil, classificada como o décimo polo têxtil nacional, sexto produtor de tecidos de algodão e terceiro produtor de fio de algodão. A cidade ocupava ainda a primeira posição no Brasil na produção de artigos felpudos, de malharia branca, de camisas de malha e de etiquetas bordadas (aproximadamente 63\% da manufatura brasileira); e era 0 segundo produtor de gazes medicinais e de roupas brancas de modo geral. ${ }^{2}$ Esses números contribuíram para que, em 1961, Blumenau figurasse como o primeiro centro industrial de Santa Catarina, com um total de aproximadamente 10 mil trabalhadores (19,2\% da mão de obra total do estado), sendo 6 mil somente no ramo têxtil, número equivalente a $67 \%$ do trabalho fabril no município. ${ }^{3}$

Em meados do século XIX, a cidade contou com uma expressiva colonização europeia, predominantemente alemã, e em sincronia com a implementação da indústria no Brasil (1880) surgiram as primeiras indústrias têxteis na região do Vale do Itajaí. Essa condição considerada "pioneira" conduziu a maior parte das análises ligadas às indústrias, com a predominância de vertentes economicistas de abordagem, com foco na idealização dos chamados "capitalistas sem capital" (Mamigonian, 1966), posição que ressalta o empreendedorismo dos empresários e fundadores das empresas locais. Portanto, praticamente são inexistentes os estudos que privilegiam análises voltadas para os próprios trabalhadores, elemento distintivo para o estudo da história social do trabalho na localidade.

Entre 1958-68, a Empresa Industrial Garcia, a Fábrica de Artefatos Têxteis Artex S/A, a Cia. Hering, a Cia. Têxtil Karsten e a Fábrica de Gazes Medicinais Cremer S/A eram 
consideradas as quatro maiores empresas da cidade, com uma média de aproximadamente 800 operários cada uma. Na constituição paisagística de Blumenau na década de 1960, as indústrias têxteis estavam escondidas no fundo dos vales, por entre as montanhas, e não concentradas nas áreas específicas destinadas à localização dos parques fabris. Dos 6 mil operários da indústria têxtil, aproximadamente 5.500 moravam em um raio inferior a $3 \mathrm{~km}$ de seu local de trabalho (Mamigonian, 1966: 466-469). Essa configuração dos espaços urbanos voltados para um enquadramento civilizatório de Blumenau pode ser equiparada ao sistema paulista de vilas operárias nos arredores das tecelagens. ${ }^{4}$ Sua característica fundamental era a localização das indústrias, residências dos diretores e serviços principais nas avenidas centrais do bairro, enquanto as moradias dos operários ficavam nos pontos de acesso com pouca estrutura. ${ }^{5}$ Isso indicava a extensão da rede de produção nos arredores das fábricas e alertava para a exacerbação de uma "insegurança estrutural" (Savage, 2004: 33), vivenciada por todos os trabalhadores a partir das dificuldades de acesso aos serviços de utilidade para suas demandas cotidianas. Além disso, tal disposição espacial contribuía para que a rotina diária fosse ordenada em torno do trabalho, atividade considerada de enobrecimento e orgulho, que centralizava boa parte da vida dos trabalhadores. Às atividades laborais atribuía-se tanto um valor ético quanto prático, tendo em vista o ideal de realização profissional.

As estreitas ligações com as atividades de trabalho são inerentes à própria existência e seria incabível praticar análises pautadas na dicotomia entre o trabalho fabril e o lar e, salvaguardadas suas diferenças, as responsabilidades diárias realizadas em ambas as esferas direcionavam para uma dúvida constante: qual delas deveria receber maior atenção e dedicação no cotidiano? 0 dia a dia - everyday (Elias, 1998: 71) - tem uma relação de simbiose com a rotina e o trabalho diário propriamente, além de vincular-se à esfera de eventos mundanos, à vida privada, às genuínas experiências e à formulação da consciência de classe.

De uma forma ou de outra, múltiplos elementos se articulavam com a produção fabril, e o trabalho se conectava às formas de convivência associadas à família e à comunidade, na composição das práticas cotidianas dos trabalhadores. Uma série de ações gerava uma constante interrelação entre a diversidade e a paridade, a divisão e a unidade, em uma contínua interação e correlação de forças, longe da estática ou fixidez (Kirk, 2004: 53). Além disso, a vida cotidiana também era forjada nas diferenças e seria incabível sugerir uma unidade capaz de parametrizar ou sistematizar suas nuances. Ainda assim, o medo da ociosidade e o orgulho gerado pela capacidade de trabalhar eram infinitamente mais valorizados, na indústria ou fora dela.

Era inegável o discurso da ética do trabalho disseminado entre os operários por meio dos jornais de circulação interna das fábricas, ${ }^{6}$ especialmente por meio de artigos que 
versavam sobre as atitudes consideradas indispensáveis ao "bom trabalhador". Um ponto fundamental era a publicação de testes voltados para a avaliação dos trabalhadores, com o propósito de verificar se atuavam de acordo com as regras. Em caso negativo, havia um direcionamento sobre as ações necessárias para atingir o perfil desejado, e se o trabalhador não obtivesse sucesso poderia perder o emprego. A norma dos testes era o trabalhador evitar o "desânimo", procurar em si próprio as falhas que levariam à "improdução" e, com afinco, modificar paulatinamente seu modo de agir em relação aos chefes e colegas. ${ }^{7}$

Por extensão, no afã de transformar o espaço fabril em um lugar familiar, muitos empresários adotaram procedimentos organizacionais que visavam o estabelecimento de uma relação livre de conflitos classistas, por meio de um ideal de reciprocidade nas relações entre patrões e operários. As referências à família compunham um recorrente discurso de unificação entre os ambientes do lar e da fábrica, e por isso persistia no sistema fabril um ideal que atribuía à indústria o apelido de "segundo lar", ou seja, local de convivência da "segunda família".

Todavia, o lar e o ambiente de trabalho contrastavam em vários aspectos, a começar pela estrutura do local de trabalho, onde as janelas altas e a falta de ventilação adequada emanavam escuridão e poeira sem fim. Norma Schwabe, funcionária da Empresa Industrial Garcia entre 1957 e 1964, descreveu o espaço industrial como um lugar onde o "pó era demais [...] e tinha aquelas janelas bem em cima, mas era muito calor, eles tinham aqueles ventiladores, mas não adiantava nada" ${ }^{8}$

As oito horas de trabalho ocupavam normalmente o dia inteiro, e na volta para casa várias tarefas deveriam ser realizadas, resultando em um constante acúmulo de trabalho. Irene Poli, operária da Empresa Industrial Garcia, mencionou que ao chegar à fábrica estava “bem cansada, nem tinha vontade de trabalhar. Eu mesma já não dava muita produção, chegava lá estava tão cansada! Eu tinha vontade de voltar, mas tinha que trabalhar! " 9 Essa realidade do mundo do trabalho deixava transparecer com nitidez as diferenças entre o lar e a fábrica.

De qualquer modo, era inegável a presença maciça de membros do núcleo familiar que trabalhavam na mesma fábrica. Também era usual a aprendizagem dos filhos dos operários ficar sob os auspícios de seus pais, cujos olhares e ensinamentos estavam eivados de instruções técnicas e padrões comportamentais acumulados ao longo da profissão. Os valores familiares e o respeito à figura paterna eram incentivados a serem reproduzidos no ambiente de trabalho por certas prescrições normativas. Muitas regras eram elaboradas por estruturas típicas de mandamentos, ${ }^{10}$ e as narrativas de conduta acionavam esse padrão bíblico, de caráter instrucional, remetendo às formas conhecidas de linguagem ao se relacionar com os 
parâmetros dogmáticos da religião cristã. No entanto, cabe atentar para o fato de que mesmo os mais duros sistemas normativos observam com atenção a preferência de seu público, seja para tentar reprimi-lo ou cooptá-lo. Por isso, a estratégia de envolvimento familiar nas relações de trabalho não era forçosamente imputada aos operários, pois havia uma complexidade nesse processo que extrapolava a mera clivagem das hierarquias. 0 uso consciente ou não de mecanismos instrutivos também dava a entender que havia um acordo entre empresários e trabalhadores na implantação desse modelo de atuação.

Sob outra perspectiva, a formulação de condutas pelo viés da conciliação reforçava a consolidação de um tipo específico de capitalismo, vinculado ao paternalismo e ao incentivo à harmonia entre patrões e operários nas indústrias têxteis. Por isso, eram constantes os discursos acerca do "clima de compreensão e boa vontade recíprocas", com a profecia de que "não há pois, ambiente para a luta de classes" 11 em Blumenau. Algumas matérias dos jornais de fábrica procuravam ditar comportamentos que extrapolavam o ambiente fabril e destinavam-se à vida privada dos trabalhadores, especialmente na coluna "Viver bem em seu lar", que retratava conselhos para o marido: "Ainda que esteja casado há muito tempo, vez por outra você deve fazer algum elogio sobre as 'habilidades culinárias' da esposa". No final, o autor aconselhava: "Não diga continuamente: - 'Se não fosse eu nesta casa... tudo iria à falência' (meu caro, nem todas as verdades podem ser ditas impunemente)" . ${ }^{12}$ Tais proposições estavam longe de configurar mera e simples brincadeira e tinham a função de tentar modelar o cotidiano a partir da valorização das relações familiares, higiene e organização doméstica.

\section{"VARria a POEIRA E TOdA AQUEla barbaridAdE": MENORES DE IDADE E FISSURAS DA REDE DISCIPLINAR INDUSTRIAL}

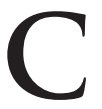
onsiderada fundamental para o funcionamento da engrenagem fabril, a família servia como parâmetro de medida da atuação dos trabalhadores no cotidiano e, apesar de suas tensões e desigualdades internas, também fomentava um senso de unidade doméstica e metas coletivas. Não era à toa que a taxa de jovens trabalhadores mantinha-se elevada na indústria têxtil e, no universo de 6 mil trabalhadores, aproximadamente 1.175 estavam na faixa etária de 14 a 18 anos, o equivalente a $20 \%$ do total. ${ }^{13}$

Era costume que os pais levassem à fábrica seus filhos que haviam completado 14 anos de idade, para iniciar suas atividades como operários. A sobrevivência era o principal fator de motivação para tal procedimento, e os menores de idade não chegavam sequer a completar o ensino básico e já eram recrutados para ajudar no sustento familiar. A partir das 
garantias e referências do pai ou da mãe, que também assumiam a responsabilidade perante a lei, o jovem trabalhador iniciava suas funções e tornava-se portador de um "Cartão de Identidade Profissional do Menor", ${ }^{14}$ expedido pelo Ministério do Trabalho, Indústria e Comércio, com dados de identificação: data de nascimento, nome dos pais ou responsáveis, nome e endereço da firma e data de registro na fábrica.

Norberto Gonçalves, tecelão, declarou que seu pai trabalhava na Empresa Industrial Garcia, e era praxe que os funcionários do departamento de pessoal consultassem as fichas dos operários para verificação da faixa etária de seus filhos. 0 procedimento padrão era chamar os pais e avisar: "Seu filho está completando 14 anos, pode colocar ele para trabalhar na empresa com a gente, tem serviço, tem vaga". Em geral, o adolescente completava 14 anos em uma semana e na outra já estava empregado na indústria têxtil. No caso específico de Norberto, suas funções iniciais consistiam na troca dos rolos de tecelagem nos teares (torcedor/remetedor). Seu contato com os tecelões, as máquinas e, principalmente, o salário melhor constituíram fatores que o estimularam a escolher a tecelagem como lugar de trabalho, com a intenção de especializar-se como tecelão perito em mecânica de teares. ${ }^{15}$

Em geral, os trabalhadores menores de idade desempenhavam as funções de varredores, ajudantes, limpadores de máquinas, enfim, atividades iniciais, que dispensavam qualificação ou técnica. Todavia, a manufatura de fios de algodão no setor de fiação e tecelagem simbolizava a síntese da precarização do trabalho dos menores, em ambiente com péssimo sistema de ventilação, poeira excessiva e outras substâncias nocivas.

Artino Leite também mencionou sua experiência como menor trabalhador, e os mecanismos de lembrança ativados por ele em seu depoimento levaram-no a frisar a "enormidade da fábrica" como aspecto crucial ao assumir suas funções iniciais como operário. Por extensão, suas impressões acerca das dimensões espaciais do setor de tecelagem não eram apenas uma distorção da memória, afinal de contas trabalhar como varredor em um local de aproximadamente $2.000 \mathrm{~m}^{2}$ exigia forte disposição. Suas palavras indicaram que era uma sala "medonha e eu varria a poeira, o pó e toda aquela barbaridade". ${ }^{16}$ Seu emprego na Empresa Industrial Garcia havia sido obtido por intermédio de seu irmão, portanto seguiu o protocolo habitual de contratação das indústrias têxteis em Blumenau, com a indicação de um responsável, o aceite via carteira do menor e a iniciação em funções sem pré-requisitos técnicos. No seu caso, o trabalho de varredor durou pouco tempo, afinal era uma espécie de teste de contratação. Logo após exerceu a função de limpador de máquinas e, com uma estopa, tirava o pó, a graxa e deixava-as "como se tivesse[m] saído da caixa". A aprendizagem acontecia na prática e não era usual frequentar cursos no início da vida profissional. Por isso, para se tornar operário, não havia exigências técnicas preliminares, apenas a vontade de aprender. 
Artino Leite, ao rememorar sua história de vida, trouxe ao tempo presente aspectos de sua constituição cultural, baseada em discursos públicos, estruturados pela classe e por convergências e divergências culturais, hierárquicas e de gênero. Sua narrativa enfatizou que em poucos meses já havia iniciado na seção de tecelagem o processo de passamento de fio, ainda como substituto, até conseguir sua própria máquina na atuação como tecelão. Seguiu à risca as instruções, subiu muito rapidamente na hierarquia fabril, aos 17 anos, já era proprietário de um "lote de terra" e alegava orgulhosamente: "em primeiro lugar eu pensava na família, no sustento da família". ${ }^{17}$ A meta coletiva era a sobrevivência, por isso, quanto mais os componentes de uma mesma família trabalhassem, mais a renda familiar seria acrescida. Assim, o sistema fabril detinha quase toda a força de trabalho familiar e criava uma espécie de relação de interdependência. A sobrevivência do grupo, em certos casos, adviria da somatória dos proventos individuais.

Não era por acaso que os menores entregavam aos pais o salário por inteiro, e normalmente somente depois de seu casamento passavam a utilizá-lo. Alguns pais também optavam por protelar o casamento dos filhos, a exemplo do que ocorreu com Paula e Mário Kratz: sua festa de casamento estava em fase de preparação, mas o pai da noiva voltou atrás no aceite. Alegou que a filha era "muito nova" e deveria "ajudar um pouco em casa porque tinha muitos irmãos" para sustentar. Tal situação perdurou por um tempo, até que a noiva engravidou e, então, "teve" que casar sem nunca ter recebido a bênção paterna. ${ }^{18}$

0 casamento também poderia ser sinônimo de autonomia em relação à utilização do salário, todavia, acarretava responsabilidades extras e mostrava as complexas circunstâncias em que eram forjadas as experiências dos trabalhadores. 0 homem casado deveria atuar como chefe de família, cumprindo suas funções de garantir o sustento da esposa e filhos, sob a ótica de que o poder principal da família caberia ao pai. O sustentáculo da sociedade era a família, e alguns operários consideravam a fábrica extensão da casa, prolongamento do meio familiar e local propício para a conquista de uma espécie de "bem comum". Norberto Gonçalves, tecelão já citado, explicitava: "Tive que trabalhar para sustentar a família, meu pai ganhava pouco porque trabalhava na tinturaria e meu irmão mais velho saiu de casa com 17 anos, ficou só eu e meu pai". ${ }^{19}$ Logo, na constituição das memórias ativadas pelos trabalhadores, as relações familiares eram centrais na rotina de trabalho, vigoravam como elemento de valoração da vida, e por isso eram um recurso de distinção no dia a dia.

Ainda assim, nas experiências cotidianas dos trabalhadores também estavam presentes atitudes consideradas não condizentes com os parâmetros comportamentais impostos pelo sistema fabril. Para livrar-se da rotina industrial, aliviar o cansaço e simplesmente se divertir, pequenas atitudes fraturavam o disciplinamento, a exemplo do costume 
de consumir doces, balas, frutas e lanches durante a execução do serviço, à revelia das regras. 0 motivo da proibição, segundo justificativas do patronato, era a distração que 0 barulho do papel de bala causava, a sujeira e as conversas que se iniciavam com esse ato. No entanto, discretamente, os trabalhadores abriam balas e outros doces sem fazer alarde e escapavam da observação dos contramestres, que talvez até soubessem, mas deixavam de lado as punições. Na Empresa Industrial Garcia havia uma estratégia para saber quando o contramestre se aproximava, momento em que os chicletes e as balas deveriam parar de revirar na boca: "Ele usava um perfume muito forte e de longe já sentíamos o cheiro, então uma dava sinal para a outra" ${ }^{20}$

Em outra situação vivida em uma seção de fiação foi relatado que em função do acúmulo de poeira da máquina em funcionamento, por recomendação superior, utilizava-se um pedaço de madeira com feltro para passar atrás do fio, retirando-se assim a sujeira acumulada. Por ser cansativo e trabalhoso, esse método era trocado com frequência e, ao invés de seguir à risca as instruções, as trabalhadoras abanavam a máquina com um pedaço de papelão para fazer a poeira voar. Isso tudo era feito na ausência de supervisores no setor e, caso a maçaneta da porta se movesse, a comunicação verbal e visual funcionaria como um alarme. Andília Bernardo contou animadamente que "a sala toda se comunicava" 21 com sinais e códigos de solidariedade indicativos da presença dos contramestres e mestres.

Também havia uma estratégia para driblar outra atividade proibida, a conversa entre os membros de uma mesma seção. No depósito da Empresa Garcia, os funcionários juntavam quatro grades utilizadas para estender o felpudo e formavam um quadrado, com um vão no centro. A costureira Ruth Missfeld declarou: "Muitas vezes a gente entrava ali e sentava. Não tinha como fazer, [...] pra ele [o gerente] encontrar a gente fazendo talvez uma brincadeira, ou alguma coisa assim". ${ }^{22}$ Comumente, os trabalhadores praticavam a "negligência" (Lüdtke, 1995) diante de certos controles empreendidos pelo sistema fabril e isso leva a crer que a agência ${ }^{23}$ dos sujeitos envolvidos nesses jogos do cotidiano também não previa ações milimétrica e cuidadosamente planejadas.

Igualmente, brotavam amizades nessas práticas sutis, especialmente por conta da necessidade de união, para que suas brincadeiras fossem bem-sucedidas. Grande parte da cumplicidade era feita por meio de contato verbal, pois durante o trabalho era proibida a comunicação entre as colegas, com recomendação para conversar "somente o necessário". Por vezes, os instrumentos de trabalho eram utilizados como disfarce para conversar: em sincronia com a colega do lado, duas mulheres se abaixavam para pegar tecido ou trocar alguma peça na máquina e, assim, ninguém "servia de testemunha". ${ }^{24}$ Muitas conversas eram articuladas por meio de gestos, outras aconteciam no banheiro, local onde podiam ser interrompidas por 
alguma advertência vinda do lado de fora. A desconfiança do tempo de permanência no banheiro era comum aos chefes, que logo tratavam de verificar a situação. 0 banheiro também era um lugar para descansar o corpo e sentar (caso das operárias que trabalhavam em pé), ou esticar o corpo depois de uma longa permanência sentada. Para evitar que ele fosse utilizado como um refúgio, algumas indústrias apelavam para o recurso da chave, que permanecia na parede, deveria ser retirada e posteriormente colocada no lugar de origem após o uso. Quem estivesse de posse da chave deveria ter clara noção de que outras pessoas estavam aguardando e, por isso, não poderia demorar. Forçosamente cada trabalhador precisaria "pensar em seu colega" 25 na constituição das relações de trabalho.

Esses exemplos são evidências de que nem tudo era diferença, disciplina e hierarquia no mundo do trabalho, pois, a despeito das desigualdades gestadas no ambiente fabril, mesmo diante dos mecanismos de controle, os operários estavam atentos às possibilidades de infiltrações para criar fissuras e brechas no sistema de disciplinamento industrial. Os trabalhadores criaram códigos de solidariedade por meio de sinais, palavras e gestos, conforme explica Artino Leite: "Quando um mestre entrava na sala, alguém fazia o sinal para os outros, sem o mestre ver, ou sequer saber. 0 sinal era botar a mão no queixo. Tinha os códigos dos operários, para todo mundo ficar alerta". ${ }^{26}$ Tais sistemas simbólicos eram conhecidos apenas pelos trabalhadores das seções que não possuíam cargos de chefia. Afinal de contas, se os contramestres, mestres e superiores soubessem dos sinais, sua função de aviso e alerta ficaria inutilizada.

Esses códigos de solidariedade dos trabalhadores geravam uma identificação entre os membros da mesma seção, embora tal particularidade não bastasse para eliminar os conflitos internos do ambiente de trabalho. Essa situação estava intimamente ligada à convivência mútua e à diversidade dos grupos sociais, onde coexistiam disputas e negociações, com interesses comuns vinculados ao sentido de grupo. Portanto, os trabalhadores demarcaram alianças, espaços e tempos peculiares para forjar suas próprias escolhas, ainda que os significados individuais fossem múltiplos.

\section{"GAROTA, NÃO ERRE SEUS CAMINHOS": A PRESENÇA FEMININA COMO MARCA DISTINTIVA NAS INDÚSTRIAS TÊXTEIS}

$\mathrm{U}$ ma das peculiaridades do conjunto da força de trabalho no segmento têxtil brasileiro era a presença maciça de mulheres no setor de produção. Em 1958, Blumenau congregava aproximadamente $66,6 \%$ do universo total de trabalhadores nos grandes estabelecimentos têxteis e, na separação por gênero, os homens correspondiam a 44,2\% (2.300) e 0 
trabalho feminino representava 55,8\%, ou seja, cerca de 2.540 mulheres, das quais 794 eram menores de idade (19,7\%) (Mamigonian, 1966: 435). As seções de tinturaria e de tecelagem eram predominantemente masculinas, enquanto a costura era composta na íntegra por muIheres, e a fiação era dividida de modo igualitário. 0 que diferia era o turno de trabalho, com homens à noite e mulheres de dia.

Em muitos casos era praticamente inexistente a presença de mulheres com faixa etária entre 25 e 30 anos, baixa atribuída ao casamento. Os ideais femininos eram propagados constantemente entre as jovens: "Garota, não erre seus caminhos! O feminino é avidez de atenção [...] A juventude de valor é autêntica, tem preocupações existenciais: de onde venho? Para onde vou? 0 que é amar? 0 que deve ser o casamento?" 27 Esses diálogos eram frequentes e tinham um cunho pedagógico, com declaração nítida do ponto de vista moral e ético voltado para as esferas do trabalho e da vida privada. Continham indicações precisas do caminho para a realização exitosa das funções femininas e atenção redobrada contra as fugas, consolidadas em uma feminilidade exagerada e pouco voltada para atitudes responsáveis e aceitas pela sociedade, em especial no tocante à valorização do casamento. As famílias consideradas ideais para trabalhar nas indústrias têxteis eram constituídas de um pai operário especializado e uma mãe dona de casa, também responsável por atividades ligadas às funções semiespecializadas na fábrica. Diante do casamento novas regras eram imputadas às trabalhadoras, e desde cedo elas eram rodeadas de normas para casar e ser uma boa mãe de família, além de a jovem solteira ser treinada a se envolver com tudo o que estivesse relacionado à administração do lar. ${ }^{28} \mathrm{Em}$ caso de seguir tais ensinamentos à risca, dificilmente ela seria apontada como transgressora das condutas femininas, e suas atenções deveriam ser redobradas para evitar que seu desempenho na família fosse prejudicado. 0 casamento deveria sintetizar a vida de todas as jovens, e parte desse imaginário era fomentada nos jornais de fábrica, em sua intencionalidade de retratar as noivas e o sonho do casamento. Além de fotos, os textos estabeleciam um contato amigável com as leitoras e aconselhavam sobre detalhes importantes da composição festiva, como a roupa, os convidados, a cerimônia, alertando: "É a sua pessoa que merece mais atenção, principalmente porque será o centro das atenções, a rainha da festa". ${ }^{29}$

Contudo, nem só de matrimônio eram compostas as publicações. Afinal de contas, não bastava casar, era preciso manter o casamento, e eram comuns as referências aos cuidados da esposa nas relações conjugais e familiares. Era corriqueira a presença de conselhos, advertências e lembretes para tornar o casamento mais harmonioso e agradável. A maioria dessas informações estava direcionada às mulheres casadas, mas não excluía as jovens solteiras, novamente encarnadas no mesmo número de mandamentos da Igreja Católica, dessa vez com regras voltadas exclusivamente para o tratamento do marido: 
(1) Estar sempre bem humorada, na hora do marido chegar, ainda que tenha tido um dia de "morte"; (2) Proceder de modo a que seu marido sinta-se sempre como seu progenitor; (3) Não humilhar o marido em público, desmentindo-o diante da sogra, empregada ou de estranhos; (4) Saber reconhecer que errou; (5) Não reservar sua alegria apenas para as visitas e estranhos; (6) Não vasculhar seus bolsos e gavetas, à procura de um fio de cabelo louro; (7) Escutar as divertidas "histórias" que ele conta sobre a "turma" do seu ambiente de trabalho; (8) Não afirmar jamais, rejubilando-se: "Eu não disse?"; (9) Receber com espírito esportivo e cordialidade os amigos de seu marido, até os ruidosos e inoportunos; (10) Não ser ciumenta das amizades do marido, nem de suas relações de família. ${ }^{30}$

O bom humor, alegria, paciência, cordialidade, obediência, passividade, docilidade e submissão eram qualidades consideradas necessariamente inerentes às mulheres. Além de serem estimuladas no ambiente familiar, essas particularidades ganharam o interesse do meio industrial, pois fomentavam aspectos de reciprocidade e boa convivência tanto dentro quanto fora da fábrica.

Mesmo desvinculando-se parcialmente da dependência financeira do marido, muitas esposas preferiam permanecer junto aos seus afazeres domésticos e maternos, com um posicionamento que declarava: "só não me sinto plenamente feliz por não poder dedicar maior tempo ao lar (...) transbordaria de alegria se pudesse dedicar-me de corpo e alma, ao lar...".31 Esse comentário demonstrava, em parte, um desejo íntimo de perpetuar a função de boa mãe e boa esposa; por outro lado, não apresentava indícios da necessidade de negar a função como operária, embora desse margem para entender o trabalho quase como um empecilho à completa realização pessoal.

A maioria das mulheres, antes do casamento, encarava o trabalho assalariado como uma fase temporária e desejável em sua experiência de vida. Para as solteiras, o dinheiro poderia ser repartido entre a compra de objetos pessoais, o passeio com amigas ou a aquisição antecipada do enxoval que, gradualmente, aumentava até o dia do casamento. No caso de restrição a determinados produtos, elas antecipavam a compra da máquina de costura (considerada imprescindível para uma esposa), jogos de cama para serem bordados por elas próprias e outros utensílios necessários para os seus afazeres no lar. Todavia, nem todas tinham contato com o salário recebido e, dependendo do acordo realizado com o pai, normalmente o dinheiro se restringia somente às necessidades básicas da casa. Era comum "colocar na mesa", ou seja, entregar aos pais o pagamento em um envelope, preferencialmente ainda fechado, sem qualquer noção sobre a quantia recebida. Isso também se aplicava a algumas esposas que, possivelmente, desconheciam o saldo total do mês de trabalho. Quando era feita a divisão, uma porção ficava para o pai, ${ }^{32}$ principalmente para acentuar seu caráter de "chefe de família" e, às vezes, a outra metade era 
destinada ao consumo próprio. Muitas trabalhadoras não julgavam que isso fosse importante e justificavam que a função do homem como gerenciador do lar era fator fundamental para a aceitação de que a remuneração masculina fosse maior que a feminina. E tal procedimento não era mera incorporação de mecanismos disciplinadores, nem tampouco falta de clareza sobre seus direitos, mas sim uma reação que mostrava a divisão e o conflito, sem necessariamente deixar de lado uma relativa "paz com a cooperação entre homens e mulheres" (Kirk, 2004: 63).

Essa diferenciação não gerava exatamente uma reação de desconforto entre as muIheres, característica evidenciada por intermédio das memórias de Andília Bernardo, operária do setor de fiação cujo trabalho consistia em operar as espulas e circundar a máquina continuamente, com o objetivo de evitar o acúmulo de poeira lançada no processo de fiação para prevenir prejuízos ao funcionamento do maquinário. Enquanto as mulheres executavam esse serviço, os homens pareciam estar menos tensos e concentrados, ficavam "conversando (...) e apenas levavam aquelas caixas de linha de um lado para o outro". ${ }^{33}$ Claramente suas lembranças estavam restritas ao setor de fiação, pouco frequentado pelos homens, a não ser os responsáveis pelo transporte de mercadorias, e por isso suas impressões e memórias do cotidiano não consideravam o trabalho nos setores de tecelagem e tinturaria que, em termos de função rotineira, estavam mais próximos de sua realidade.

Nos anos de 1960 também havia um discurso que atribuía ao comportamento das muIheres instruídas e independentes financeiramente a pecha de desviantes, pois soavam como uma ameaça aos preceitos comportamentais, desestabilizando os papéis convencionados para homens e mulheres. Em geral, o estereótipo atribuído às mulheres indicava a necessidade de ser "pura" e praticar apenas atividades próprias ao gênero, sem ampliar seus pensamentos para atividades onde pudessem exercer sua intelectualidade, possibilitando questionamentos acerca de sua figura e atitudes incompatíveis com as condutas esperadas.

Por isso, era usual que o contingente de trabalhadores da fábrica fosse renovado com membros da própria família. Algumas mães com filhos de 14 anos ou mais regressavam às tarefas domésticas e deixavam seu lugar na fábrica a cargo de uma filha, ou então procuravam encontrar uma vaga para estabelecer seus filhos. Quem ocupasse o lugar das mães deveria compensar a lacuna deixada no setor e renovar o contingente de solteiras no espaço fabril, uma condição civil valorizada no aspecto financeiro da fábrica. Era mais vantajoso para a elite empresarial contratar jovens solteiras, cujo salário de aprendiz era inferior, além de evitar despesas com a maternidade em virtude de uma gestação, sendo a faixa etária entre 25 a 30 anos considerada propícia ao nascimento de filhos.

Por outro lado, parte dos industriais entendia que as moças, justamente por conta de sua juventude, não apresentavam maturidade suficiente, e o trabalho não era tão produtivo, 
especialmente devido à falta de experiência. Às trabalhadoras, ao contrário dos patrões, não era apenas a produtividade que interessava, e por isso Andília Bernardo considerava que "era muito nova e não tinha resistência". ${ }^{34}$ Obviamente, o fato de que o corpo adolescente estava em fase de crescimento e não se acostumava facilmente a um ritmo intenso de trabalho era desconsiderado pelos patrões. Além do mais, o cansaço excessivo em decorrência do trabalho incidia prejudicialmente sobre o desenvolvimento físico e mental das jovens trabalhadoras.

Ao completar 14 anos, as moças guardavam as bonecas, ${ }^{35}$ abandonavam os estudos e ingressavam no universo social do trabalho. A máquina de costura que antes divertia tornava-se instrumento de trabalho e meio de sobrevivência. Claramente não havia um período de preparação que suavizasse a passagem entre essas duas fases da vida das mulheres. De um dia para o outro, era necessário despir-se da criança para tornar-se uma adulta e trabalhar na fábrica. 0 contato inicial com o trabalho assalariado assustava, e o primeiro dia era considerado o "pior, porque a gente nunca tinha saído de casa. Esse dia não passava! Meu Deus, que dia! Mas depois foi acostumando...". ${ }^{36}$ Essa memória ligava-se diretamente à comparação com o ambiente doméstico, anteriormente predominante na vida das operárias, quando vigorava um relacionamento muito restrito com o mundo público e sem qualquer vínculo com 0 trabalho assalariado.

Algumas jovens eram provenientes de cidades vizinhas a Blumenau e se separavam da família para reforçar o orçamento familiar. A grande maioria morava nas casas de parentes e a nova vida não envolvia apenas obrigações, sobretudo porque ao sair de casa era comum a conquista de um pouco mais de autonomia do que se a jovem estivesse sob os olhares dos pais. Em contrapartida, a relativa flexibilidade dos horários de quem trabalhava no campo cedia lugar ao rígido tempo da fábrica, fator que gerava uma difícil adaptação inicial, conforme explica Irene Poli: "No início foi muito difícil! A gente trabalhava no turno geral, das $7 \mathrm{~h}$ às $17 \mathrm{~h}$. Às $12 \mathrm{~h}$ saía, daí começava $13 \mathrm{~h}$ ou 12h30, dependendo do serviço. Tinha refeitório naquele tempo (...) mas tinha que pagar. Então eu já fazia a marmitinha em casa" ${ }^{37}$

Essa memória evoca um início complicado, sobretudo por conta da ruptura causada na vida cotidiana e das mudanças associadas nos primeiros tempos da condição operária. No entanto, algumas trabalhadoras referenciam esse esforço de adaptação à indústria do ponto de vista da libertação parcial dos serviços domésticos. Além disso, indicam que também a mudança se tornava uma possibilidade de abertura em relação à sua restrita perspectiva de vida, voltada exclusivamente para o lar. Isso acontecia principalmente em função da ideia de que o trabalho desenvolvido em casa pela mãe/esposa/filha não era considerado uma profissão e, por isso, não tinha valor monetário algum. Normalmente essa mão de obra era necessária para a manutenção da economia familiar ou, por vezes, surgia da vontade própria 
de jovens e adultas que desejavam "escapar" de um futuro previamente ditado pela família e pela sociedade.

Tanto na fábrica quanto no lar, as mulheres executavam seus serviços com destreza, minúcia e rapidez, porém essas características praticamente não eram vistas como qualificações para o trabalho, nem tampouco estavam perceptíveis aos olhos masculinos, pois eram consideradas inatas e próprias da natureza feminina. A mulher recebeu destaque no âmbito público por essas "qualidades", que poderiam ser aproveitadas em diversos setores da sociedade, já que no trabalho remunerado normalmente transferiam para o serviço que executavam a mesma seriedade e esforço com que encaravam as tarefas domésticas. Além disso, certos hábitos como fumar não faziam parte da rotina da maioria, e a distração também era pouco praticada, em função dos compromissos do lar e da fábrica. Em suma, convencionou-se que as mulheres eram "mais dóceis, mais pacientes, mais dedicadas ao serviço" (Pena, 1981: 159). Esse discurso de padronização das condutas procurava perpetuar a "docilidade" da mulher. Como era seu dever cultivar a harmonia no lar e na família, acreditava-se que ela pouparia conflitos no ambiente de trabalho, pois afinal em "contato com o público ela colocaria em prática toda a diplomacia e doçura femininas". ${ }^{38}$ Desse modo, evitaria que brigas ou discussões ganhassem proporções maiores e estabeleceria um espaço agradável de trabalho.

Ao trabalhar na fábrica, as operárias tinham a obrigação de transferir para o trabalho todas as provas de sua educação moral e de seu comportamento exemplar, para merecer "0 máximo respeito, demonstrado pela sua conduta impecável diante de seus chefes e colegas" ${ }^{39}$ A ideia era que as mulheres acatassem os conselhos recebidos para evitar que a harmonia familiar se desestabilizasse. As tentativas de controle intencionavam esvaziar o potencial de conflito, com base na disseminação constante dos ideais de desigualdade entre os indivíduos.

No caso das indústrias têxteis de Blumenau a relação familiar entre chefes e subordinados também estava associada ao fato de que a maioria delas era administrada por famílias e predominava um constante estímulo ao sistema de cooperação entre operários e industriais, em uma relação de reciprocidade, em que os trabalhadores ajudariam no incremento da indústria e, em troca, receberiam oportunidades de emprego para seus filhos. Isso não significava que os funcionários das indústrias têxteis vivessem em um mundo de resignação a um destino inescapável, voltado apenas ao lar e à família, pois sua vida comunitária no bairro possibilitava uma interconexão entre as esferas do trabalho, da moradia e da família, com uma vinculação inextricável entre condições materiais, opções políticas e práticas culturais (Duarte, 2002: 39).

Afinal de contas, as ações humanas não são passíveis de controle na íntegra e muitas atitudes destoavam do modelo disciplinador desejado e implementado nas relações de poder 
intrínsecas à fábrica. As mulheres operárias não eram vítimas do trabalho fabril, portanto, sua agência não se justificava apenas mediante o disciplinamento imposto pelos chefes de seção ou pelo patrão. Tampouco poderiam ser consideradas passivas ou rebeldes, mas sim ativas e aptas a burlar proibições com uma boa dose de criatividade, sem necessariamente criar conflitos declarados e abertos, preferindo lançar mão de recursos mais sutis na constituição de si perante a sociedade. Muitas operárias evitavam se posicionar contra as regras, porque os valores estavam acima de tudo e a educação e as boas maneiras eram uma forma de honrar e respeitar a família de origem. Era comum os jornais de fábrica divulgarem proposições educativas vinculadas à esfera doméstica, com campanhas para a organização do lar, o desenvolvimento de atividades consideradas saudáveis e o exercício de funções morais e cívicas convenientes. Por outro lado, mesmo diante de uma relação desigual de forças, as ações humanas são imprevisíveis e os trabalhadores poderiam se apropriar das condutas exemplares, tão propagadas nos jornais de fábrica, a partir de experiências próprias e incessantes negociações, pautadas em um vasto campo de possibilidades históricas.

\section{CONSIDERAÇÕES FINAIS}

despeito da hierarquia fabril e das constantes ações disciplinares empreendidas pelo
sistemastrial, o cotidiano e a rotina dos trabalhadores se constituíam com atenção redobrada às atividades laborais, interconectadas a uma infinidade de proposições que extrapolavam o chão da fábrica, na medida em que o sustento e o ideal de "bom trabalhador" não eram os únicos referenciais de vida para os operários. A família também abrigava fraturas e desigualdades de gênero, portanto estava longe de ser uma unidade indissociável, e concomitantemente encontrava-se vinculada ao mutualismo de seus componentes, tanto em relação à sobrevivência quanto à troca de experiências. Coexistiam diferenças de padrões de vida, cultura, política e gênero, sem necessariamente gerarem apenas conflitos, pois a mobilidade social e a melhoria das condições de vida comportavam elementos de unidade, em simbiose com a formação dos conjuntos, muitas vezes fracionados, dos mundos do trabalho.

Todavia, ainda que o sistema produtivo investisse na interferência constante no dia a dia dos trabalhadores, seus comportamentos não eram passíveis de controle, e predominava a diversidade no vínculo entre a fábrica, a moradia e a comunidade do bairro. Os trabalhadores, portanto, não eram vítimas do trabalho fabril e praticavam ações concretas no cotidiano, mediante a composição de fraturas na rede de disciplinamento fabril. Suas estratégias criativas de atuação comportavam atitudes sutis de inversão da ordem disciplinar, tais como: consumo 
de doces durante a execução do serviço; uso de caixas e equipamentos para construir uma área para conversas e brincadeiras; além da criação de códigos pautados em sinais e gestos que indicavam a presença dos mestres e contramestres. Isso ocorria por intermédio do uso da criatividade e das trocas de experiência, sem necessariamente causar tensões abertas, por meio do uso de recursos mais sutis na constituição de si perante o mundo do trabalho na indústria têxtil.

\section{NotAS}

1 Distante cerca de $150 \mathrm{~km}$ de Florianópolis, até 1934 Blumenau apresentava um território que abrangia $10.610 \mathrm{~km}^{2}$, área que paulatinamente foi desmembrada. Entre 1958 e 1968, a cidade contava com $540 \mathrm{~km}^{2}$ e uma população em torno de 80 mil habitantes.

2 Produção Industrial Brasileira, n. 32, 1956, citada por Armen Mamigonian (1966).

$3 \mathrm{Em}$ termos de quantidade de mão de obra, os demais segmentos industriais eram: instrumentos musicais e brinquedos, com 8,7\%; transformação de metais, com 6,8\%; indústrias alimentares e bebidas, com 4\%, e preparação de tabaco, com 3\%. Na década de 1960, Blumenau produzia a totalidade das gaitas de boca nacionais e boa parte dos acordeões, além de $20 \%$ das pás, dados que explicam o número de trabalhadores também nessas indústrias.

4 José Sérgio Leite Lopes, em seu estudo sobre a Companhia de Tecidos Paulista, considera que as fábricas com vilas operárias apresentam "uma configuração de uma estrutura de relações sociais de dominação dentre outras configurações possíveis no interior do modo de produção capitalista e no interior do conjunto de relações entre a classe operária e o patronato" (1988: 18).

5 Armen Mamigonian classificou o espaço do entorno das fábricas de Blumenau como organizado no formato de "espinha de peixe", subdividido em: 1) espinha dorsal, equivalente às avenidas principais e 2) espinhas tentaculares, para as áreas menos urbanizadas (1966: 472).

6 O Radar Sulfabril, Mensageiro Artex, Noticiário Cremer e Informativo Hering eram periódicos de circulação interna nas principais indústrias têxteis de Blumenau, em geral editados mensalmente, com abordagens que referenciavam curiosidades, relações de trabalho, coluna feminina, aniversários de tempo de serviço dos trabaIhadores, desporto e outras temáticas. Os colunistas eram, em sua maioria, vinculados ao setor administrativo, e as diferenças entre as linhas editoriais eram sutis, com destaque para a coluna "Álbum da Família", que entrevistava operários e publicava regularmente seus depoimentos (Ferreira, 2015).

7 Guino José Sgrott, "Relembrando boas maneiras: trabalho", O Radar Sulfabril, Blumenau, set. 1965. Arquivo Histórico José Ferreira da Silva (AHJFS).

8 Norma Schwabe, entrevista concedida em abril de 2001 ao projeto "A força de trabalho feminina na indústria têxtil regional: estudo das formas de sociabilidade das mulheres operárias do Vale do Itajaí (1940-1970)", coordenado pela autora. Essas narrativas e os demais depoimentos orais estão envoltos na problemática da memória, suas limitações, lacunas e distorções. Todavia, a reconstrução do passado por intermédio da história oral de vida pressupõe uma seleção que "tanto o legitimava, quanto o dotava de sentido" para os próprios entrevistados. E, claro, aqui não é viável entrar nos meandros teórico-metodológicos da história oral, cujo 
cerne reside nos processos subjetivos do testemunho, com destaque para o universo cultural dos atores históricos, diante da "complexidade encontrada nas vidas e nas experiências históricas daqueles que as contam" (James, 2004: 191-193).

9 Irene Rosa Poli, entrevista concedida em junho de 2001 ao projeto "A força de trabalho feminina..." , cit.

10 Trecho do artigo "Os 15 princípios do bom empregado": "1. 0 bom empregado faz do trabalho um meio de aperfeiçoamento e valorização e não um fim em si mesmo. [...] 4. Ele trabalha sem afobamento, não perdendo tempo em conversas e futilidades. 5. Ele tem iniciativa própria [...]". O Radar Sulfabril, Blumenau, jul. 1965 (AHJFS).

11 "Exaltação ao trabalho", Mensageiro Artex, Blumenau, mai. 1964 (AHJFS).

12 João Maria Mosimann, "Viver bem em seu lar", O Radar Sulfabril, Blumenau, dez. 1967 (AHJFS).

13 Esses dados correspondem aos números do Registro Industrial de 1958 utilizado por Armen Mamigonian, portanto, não há indícios das variações numéricas que porventura ocorressem no sistema fabril.

14 Norberto Gonçalves, Cartão de Identidade Profissional do Menor (17/08/1960). Acervo pessoal da autora.

15 Norberto Gonçalves, entrevista concedida em maio de 2003 ao projeto "A vida fora das fábricas", coordenado pela autora.

16 Artino Leite, entrevista concedida em julho de 2004 ao projeto "Trabalho e sociedade: o cotidiano dos operários da indústria têxtil de Blumenau (1950-1970)", coordenado pela autora.

17 Idem.

18 Paula e Mário Kratz, entrevista concedida em março de 2002 ao projeto "A vida fora das fábricas", cit.

19 Norberto Gonçalves, entrevista citada.

20 Norma Schwabe, entrevista citada.

21 Andília Bernardo, entrevista concedida em maio de 2001 ao projeto "A força de trabalho feminina..." cit.

22 Ruth Missfeld, entrevista concedida em outubro de 2001 ao projeto "A força de trabalho feminina..." cit.

23 Agency, ou agência humana, estuda os dispositivos de ação ativados em determinadas circunstâncias por certos grupos sociais para constituir sua experiência social/cultural e representar percepções de si e do mundo (Thompson, 1958).

24 Norma Schwabe, entrevista citada.

25 Ingeborg Härbe, entrevista concedida em maio de 2001 ao projeto "A força de trabalho feminina..." , cit.

26 Artino Leite, entrevista citada.

27 "A mulher e seus caminhos", Mensageiro Artex, Blumenau, set. 1966.

28 Haraldo Germer, "O álbum da 'família'", O Radar Sulfabril, Blumenau, jan. 1965, p. 3.

29 o Radar Sulfabril, Blumenau, abr. 1966.

30 Leonídia Silva, "As pequenas atenções femininas - Coluna feminina", O Radar Sulfabril, Blumenau, mar. 1966, p. 8. 
31 Espêrio Campestrino, "O álbum da família", O Radar Sulfabril, Blumenau, mar. 1968.

32 Mencionamos apenas o pai, porque a mãe era deixada alheia à situação financeira da família; só era diferente quando as relações familiares eram outras e a mãe também trabalhava.

33 Andília Bernardo, entrevista concedida em maio de 2001 ao projeto "A força de trabalho feminina...", cit.

34 Idem.

35 Ingeborg Härbe, entrevista citada.

36 Norma Schwabe, entrevista citada.

37 Irene Rosa Poli, entrevista citada.

38 Leonídia Silva, "A coluna feminina", O Radar Sulfabril, Blumenau, dez. 1965, p. 4. (AHJFS).

39 Leonídia Silva, "A coluna feminina", O Radar Sulfabril, Blumenau, jan. 1965. (AHJFS).

\section{REFERÊNCIAS BIBLIOGRÁFICAS}

DUARTE, Adriano. Cultura popular e cultura política no após-guerra: redemocratização, populismo e desenvolvimentismo no bairro da Mooca, 1942-1973. Tese (Doutorado em História), Campinas, Unicamp, 2002.

ELIAS, Norbert. On the concept of everyday life. In: GOUDSBLOM, Johan \& MENNELL, Stephen (org.). The Norbert Elias reader. a biographical selection. Malden: Blackwell, 1998.

FERREIRA, Cristina. Nas malhas da história: sociabilidade e política no cotidiano dos trabalhadores têxteis de Blumenau. Tese (Doutorado em História), Campinas, Unicamp, 2015.

JAMES, Daniel. Contos narrados nas fronteiras: a história de dona Maria, história oral e questões de gênero. In: BATALHA, Claudio H. M.; SILVA, Fernando Teixeira da \& FORTES, Alexandre (org.). Culturas de classe: identidade e diversidade na formação do operariado. Campinas: Editora da Unicamp, 2004.

KIRK, Neville. Cultura: costume, comercialização e classe. In: BATALHA, Claudio H. M.; SILVA, Fernando Teixeira da \& FORTES, Alexandre (org.). Culturas de classe: identidade e diversidade na formação do operariado. Campinas: Editora da Unicamp, 2004.

LOPES, José Sergio Leite. A tecelagem dos conflitos de classe na "cidade das chaminés". São Paulo: Marco Zero/Universidade de Brasília, 1988.

LÜDTKE, Alf. The History of Everyday Life: Reconstructing Historical Experiences and Way of Life. Princeton: Princeton University Press, 1995, p. 198-251.

MAMIGONIAN, Armen. Estudo geográfico das indústrias de Blumenau. In: Separata da Revista Brasileira de Geografia, Rio de Janeiro, Instituto Brasileiro de Geografia e Estatística, Conselho Nacional de Geografia, 1966.

PENA, Maria Valéria Junho. Mulheres e trabalhadoras: presença feminina na constituição do sistema fabril. Rio de Janeiro: Paz e Terra, 1981. 
SAVAGE, Mike. Classe e história do trabalho. In: BATALHA, Claudio H. M.; SILVA, Fernando Teixeira da \& FORTES, Alexandre (org.). Culturas de classe: identidade e diversidade na formação do operariado. Campinas: Editora da Unicamp, 2004.

THOMPSON, E. P. Agency and choice - I (A replay to criticism). The New Reasoner, n. 5, p. 89-106, summer 1958. 